\title{
PERÍODO DE UTILIZAÇÃO INDUSTRIAL DE CULTIVARES DE SORGO SACARINO VISANDO A PRODUÇÃO DE ETANOL
}

\author{
ALEXANDRE MATOS MARTINS ${ }^{1}$, RAFAEL AUGUSTO DA COSTA PARRELLA ${ }^{2}$, \\ DANIELA DE CARVALHO LOPES ${ }^{3}$, ROBERT EUGENE SCHAFFERT ${ }^{2}$, \\ NÁDIA NARDELY LACERDA DURÃES PARRELLA ${ }^{3}$, WÂNIA DOS SANTOS NEVES ${ }^{4}$ \\ e ANA PAULA COELHO MADEIRA SILVA ${ }^{3}$
}

\author{
${ }^{1}$ Empresa de Assistência Técnica e Extensão Rural do Estado de Minas Gerais, MG, Brasil, \\ alexandre.martins@emater.mg.gov.br \\ ${ }^{2}$ Empresa Brasileira de Pesquisa, Embrapa Milho e Sorgo, Sete Lagoas, Mg, Brasil, \\ rafael.parrella@embrapa.br; robert.schaffert@embrapa.br \\ ${ }^{3}$ Universidade Federal de São João del-Rei, UFSJ, Sete Lagoas, MG, Brasil, \\ danielalpoes@ufsj.edu.br;nadia@ufsj.edu.br; anapaula@ufsj.edu.br \\ ${ }^{4}$ Empresa de Pesquisa Agropecuária de Minas Gerais, EPAMIG, Prudente de Morais, MG, Brasil,wanianeves@epamig.br
}

Revista Brasileira de Milho e Sorgo, v.16, n.2, p. 217-231, 2017

\begin{abstract}
RESUMO - Uma característica importante do sorgo sacarino é o Período de Utilização Industrial (PUI), necessário para o planejamento da colheita e o processamento. O objetivo do presente trabalho foi estabelecer o PUI de cinco cultivares comerciais de sorgo sacarino visando a produção de etanol na região Central de Minas Gerais. O delineamento experimental foi o de blocos casualizados com três repetições, num esquema em parcelas subdivididas. Características avaliadas: florescimento, produção de massa verde (PMV), sólidos solúveis totais (SST), açucares redutores totais (ART), teor de sacarose aparente (POL), açucares totais recuperáveis (ATR), produtividade de etanol por tonelada (PROTE) e PUI. Foram verificadas diferenças entre as duas safras agrícolas, cultivares e épocas de colheita para todos os caracteres agronômicos e industriais do sorgo sacarino. A interação safras x épocas de colheita foi significativa para todos os caracteres. Já a interação cultivares x épocas de colheita mostrou-se significativa $(P \leq 0,01)$ para quase todos os caracteres, exceto PMV. Houve interação safras x cultivares x épocas de colheita significativa para SST, ART, POL, ATR, e PROTE. No primeiro ano de semeadura, as variedades BRS 511, BRS 508 e BRS 509 apresentaram melhor desempenho agroindustrial visando a produção de etanol quando comparadas com os híbridos XBSW80147 e Sugargraze. As cultivares BRS 511, BRS 508 e BRS 509 apresentaram-se dentro dos limites mínimos de qualidade e produtividade estabelecidos na safra 2011/2012. Já na safra 2012/2013 apenas o BRS 508 apresentou-se dentro de todos os padrões estipulados em razão da ocorrência de acamamento. Baseado nos resultados obtidos, destacaram-se as variedades BRS 508, BRS509 e BRS511, considerando os caracteres agroindustriais e PUI para a produção de etanol. O melhor período de colheita considerando as características agroindustriais foi dos 100 aos 130 dias após o semeio, apresentando pico aos 113. As cultivares avaliadas apresentaram períodos de utilização industrial diferentes, com as variedades apresentando PUI superior a 30 dias e os híbridos com PUI inferiores a 20 dias.
\end{abstract}

Palavras-chave: Sorghum bicolor, biocombustíveis, agroindústria.

\section{PERIOD OF INDUSTRIAL USE}

\section{OF SWEET SORGHUM VARIETIES AIMING ETHANOL PRODUCTION}

\begin{abstract}
An important parameter of sweet sorghum is the Period of Industrial Utilization (PIU), necessary for industrial management to provide high quality feedstock 24 hours per day during the period of industrial processing. The objective of this study was to establish maturity curves and PIU for five commercial cultivars of sweet sorghum for ethanol production in the Central region of Minas Gerais. A randomized complete block design with three replications in a split plot (seven-day harvest intervals) scheme was used during two seasons to determine the following parameters: days to flower, production of fresh biomass (PFB), total soluble solids in the juice (TSS), total sugars (TS), apparent sucrose content (ASC), total recoverable sugars (TRS), ethanol productivity per ton (EPT) and PIU. Differences were found between the two agricultural seasons, cultivars and harvest periods for all the agronomic and industrial traits of sweet sorghum. The yield $\mathrm{x}$ harvest period interaction was significant for all parameters evaluated. The interaction cultivar $\mathrm{x}$ harvest period was highly significant for all parameters except PFB. There was significant year $\mathrm{x}$ cultivars interaction for harvest period for SST, TS, ASC, TRS and EPT. The varieties BRS 511, BRS 508 and BRS 509 showed better agro-industrial performance for producing ethanol compared to sweet sorghum hybrids XBSW80147 and Sugargraze. The varieties BRS 511, BRS 508 and BRS 509 were within the PIU thresholds for quality and productivity in the 2011/2012 season. However, only BRS 508 was within the quality threshold for the 2012/2013 harvest, due to the occurrence of lodging. Based on these results, the varieties BRS 508, BRS 509 and BRS 511 can be considered for ethanol production. The best harvesting period considering the agro-industrial characteristics was between 100 and 130 days after planting, with peaking at 113 days. The cultivars showed different periods of industrial use, with the varieties presenting PIU values of more than 30 days and the hybrids with PUI values less than 20 days. Keywords: Sorghum bicolor L. Moench, biofuels, agribusiness.
\end{abstract}


A demanda mundial por combustíveis obtidos a partir de fontes renováveis tem se expandido rapidamente nos últimos anos por causa da preocupação com a redução do volume de emissões de gases causadores do efeito estufa (United Nations Conference on Sustainable Development, 2012). O Brasil é um dos países pioneiros na substituição de combustíveis de origem fóssil, como gasolina, óleo diesel, gás natural e carvão mineral, por biocombustíveis. Com a abertura deste cenário, o setor sucroalcooleiro do Brasil tornou-se o mais competitivo do mundo, apresentando os maiores níveis de produtividades e de rendimento industrial, quando comparado aos seus principais concorrentes.

Dentre as diversas matérias-primas renováveis e sustentáveis disponíveis atualmente, para auxiliar o complexo produtivo do etanol, destaca-se o sorgo sacarino, que possui colmo suculento e caldo semelhante ao da cana-de-açúcar, apresenta açúcares fermentescíveis e pode servir para a produção de etanol utilizando as instalações já existentes nas usinas sucroalcooleiras. Neste atual cenário da agricultura brasileira, a produção de bioenergia, numa visão sustentável, passa, obrigatoriamente, pela diversificação de matérias-primas (Macedo, 2013).

Uma característica muito importante na cultura do sorgo sacarino que deve ser estudada é o Período de Utilização Industrial (PUI), necessário para planejamento de colheita e processamento de matéria-prima, que deve ser o maior possível e ter mínimo de 30 dias. Essa característica varia em função da cultivar, do manejo e do local (Parrella \& Schaffert, 2012).

Análises que avaliam épocas de colheita, características morfoagronômicas da cultura e bioquímicas do caldo se fazem necessárias para caracterizar o PUI das cultivares de sorgo sacarino, auxiliando no melhor aproveitamento da cultura. Assim, este traba- lho foi desenvolvido com o objetivo de estabelecer o PUI de cinco cultivares comerciais de sorgo sacarino visando a produção de etanol na região Central de Minas Gerais.

\section{Material e Métodos}

O trabalho foi realizado no campo experimental da Embrapa Milho e Sorgo, Sete Lagoas-MG (latitude $19^{\circ} 28^{\prime} \mathrm{S}$, longitude $44^{\circ} 15^{\prime} \mathrm{W}$ e altitude de 732 $\mathrm{m})$, em um Latossolo vermelho distrófico. O clima característico é Cwa (Köppen) com inverno seco e temperatura média do ar do mês mais frio superior a $18^{\circ} \mathrm{C}$. Os experimentos foram implantados nas safras agrícolas 2011/2012 e 2012/2013, coincidindo com o período chuvoso característico da região. As semeaduras foram feitas em 21/11/2011 e 04/12/2012, respectivamente. Dois dias após a realização de aração e gradagem do solo, as semeaduras foram feitas de forma mecanizada utilizando semeadora-adubadora convencional.

Com base nos resultados da análise de solo, foi realizada adubação de semeadura com $350 \mathrm{Kg} \cdot \mathrm{ha}^{-1}$ do formulado N-P-K (08-28-16) acrescido do nutriente boro; 50 Kg.ha-1 de FTE BR12 e $200 \mathrm{Kg}^{-1 a^{-1}}$ de ureia em cobertura 20 dias pós-semeadura. Após 15 dias de emergência, realizou-se o desbaste, em que foram mantidas na área oito plantas por metro linear, totalizando 40 plantas por linhas de cinco metros. O controle de plantas daninhas foi efetuado pós-semeadura com a utilização de atrazina, na dosagem recomendada, sendo complementado pela capina manual. Foi realizada irrigação suplementar no período de estabelecimento da cultura e nos períodos de veranicos, sempre que necessário.

O experimento em cada ano foi conduzido utilizando delineamento em blocos casualizados, com 
três repetições, num esquema em parcelas subdivididas. Foram avaliadas 5 cultivares de sorgo sacarino nas parcelas experimentais, sendo 3 variedades (BRS 508, BRS 509 e BRS 511), desenvolvidas pelo programa de melhoramento da Embrapa Milho e Sorgo, e dois híbridos comerciais, Sugargraze e XBSW80147, desenvolvidos pela Advanta Sementes e Canavialis, respectivamente. Cada parcela foi subdividida em oito subparcelas, ou seja, oito fileiras de $5 \mathrm{~m}$, espaçadas $0,70 \mathrm{~m}$, com população de 120 mil plantas ha-1. Desta forma, foram realizadas oito colheitas, em intervalos de 7 em 7 dias, a partir de 87 dias após o semeio (DAS), em uma subparcela de cada cultivar nas três repetições.

Foram avaliadas as seguintes características: a) florescimento, considerando o número de dias ocorridos entre a semeadura e a data em que $50 \%$ das plantas apresentaram antese, na parcela e b) peso de massa verde total (PMV) através da pesagem das plantas das subparcelas sem panículas e o valor convertido em t.ha' . $^{-}$

Para avaliação dos caracteres industriais ligados à produção de etanol, foi realizada a extração do caldo de uma amostra de 8 plantas inteiras (escolhidas aleatoriamente), sem panículas, colhidas na subparcela semanalmente. Em seguida, as plantas foram desintegradas em desfibrador e homogeneizadas. Posteriormente, foi retirada uma subamostra de 500 $\pm 0,5$ g para extração do caldo em prensa hidráulica, modelo PHS250, com pressão mínima e constante de $250 \mathrm{kgf} \mathrm{cm}^{-2}$ sobre a amostra, durante o tempo de 1 minuto.

No caldo extraído foi determinado o teor de sólidos solúveis totais (SST), em graus brix $\left({ }^{\circ} \mathrm{B}\right)$, com refratômetro digital de leitura automática e obtida a leitura sacarimétrica (LZ), em grauz Z ( ${ }^{\circ} \mathrm{Z}$ ) (um centésimo de grau de açúcar) utilizando a espectrofoto- metria de Infravermelho Próximo (NIR), em equipamento NIRFlex 500, marca Buchi. Adicionalmente, obteve-se o peso do bolo úmido (PBU), bagaço remanescente após a extração do caldo. Este bagaço foi seco em estufa a $105{ }^{\circ} \mathrm{C}$ por 72 horas para obtenção do peso do bolo seco (PBS). Em seguida, utilizou-se o SST, LZ, PBU e PBS para estimar os açúcares redutores totais (ART), em \%, teor aparente de sacarose (POL), açúcares totais recuperáveis (ATR), em kg de açúcares recuperáveis por tonelada de biomassa do sorgo e produtividade de álcool hidratado (PROTE), em litros de álcool por tonelada de biomassa do sorgo, de acordo com o Conselho dos Produtores de Canade-Açúcar, Açúcar e Álcool do Estado de São Paulo (2006). Para estimar o ART, utilizou-se a expressão "ART = açúcares redutores + Pol / 0,95"; para estimar o POL, utilizou-se a expressão "POL $=(1,00621$ x LZ $+0,05117) \times(0,26050,0009882 \times \mathrm{SST})$ "; para estimar o ATR, utilizou-se a expressão "ATR $=10$ x POL x 1,05263 x 0,905 + 10 x AR(açúcares redutores) $\mathrm{x}$ 0,905"; e para estimar o PROTE, utilizou-se a expressão "PROTE = ART x 10 x 0.6475 x 0.85". Desta forma, foram realizadas as análises estatísticas para os seguintes caracteres: florescimento, PMV, SST, ART, POL, ATR e PROTE.

O período de utilização industrial (PUI) foi avaliado relacionando-se os dias após a semeadura (DAS) com os teores de açúcares observados. Além da observação de todas as características necessárias para a manutenção dos padrões mínimos, foram relacionados, dentre as características agroindustriais avaliadas, os teores de SST $\left(15^{\circ} \mathrm{B}\right)$, ART $(12,5 \%)$ e ATR ( $80 \mathrm{~kg}$ de açúcar por tonelada de biomassa). Assim, o PUI foi o período no qual o sorgo manteve os teores mínimos de açúcares, possibilitando uma fermentação com alta eficiência e qualidade visando maximizar a produção de etanol (Prasad et al., 2007). 
Os dados, após os testes de normalidade e homocedasticidade, foram submetidos à análise de variância conjunta, considerando-se as safras agrícolas 2011/2012 e 2012/2013 para todas as características, utilizando o modelo estatístico abaixo. As análises estatísticas foram realizadas através do programa estatístico Sisvar ${ }^{\circledR}$ (Ferreira, 2010). As variáveis de natureza qualitativa foram avaliadas segundo o teste de Scott-Knott, a 5\% de probabilidade.

$\mathrm{Y}_{\mathrm{ijk} k}=\mu+\alpha_{\mathrm{i}}+\mathrm{b}_{\mathrm{j}(\mathrm{k})}+\gamma_{\mathrm{k}}+(\alpha \gamma)_{\mathrm{ik}}+\varepsilon_{\mathrm{ij}(\mathrm{k})}+\rho_{1}+(\gamma \rho)_{\mathrm{kl}}+(\alpha \rho)_{\mathrm{il}}+(\alpha \gamma \rho)_{\mathrm{ikl}}+\xi_{\mathrm{ijk}}$

Onde:

$\mathrm{Y}_{\mathrm{ijk}}$ : é o valor observado para a variável em estudo; $\mu$ : média geral de todas as unidades experimentais; $\alpha_{i}$ : efeito do i-ésimo nível do fator Cultivar $(i=1 . . .5)$; $\mathrm{b}_{\mathrm{j}(\mathrm{k})}$ : efeito do j-ésimo Bloco na k-ésima Safra $(\mathrm{j}=$ $1 \ldots 3, \mathrm{k}=1,2)$;

$\gamma_{\mathrm{k}}$ : efeito do k-ésimo nível do fator Safra $(\mathrm{k}=1,2)$; $(\alpha \gamma)_{\mathrm{ik}}$ : efeito da interação do i-ésimo nível do fator Cultivar com o k-ésimo nível do fator Safra; $\varepsilon_{\mathrm{ij}(\mathrm{k})}$ : erro associado à parcela; $\rho_{1}$ : efeito do 1-ésimo nível do fator Época $(1=1 \ldots 8)$; $(\gamma \rho)_{\mathrm{kl}}$ : efeito da interação do k-ésimo nível do fator Safra com o 1-ésimo nível do fator Época; $(\alpha \rho)_{\mathrm{il}}$ : efeito da interação do i-ésimo nível do fator Cultivar com o l-ésimo nível do fator época; $(\alpha \gamma \rho)_{\mathrm{ikl}}$ : efeito da interação do i-ésimo nível do fator Cultivar com o k-ésimo nível do fator Safra e o l-ésimo nível do fator Época; $\xi_{\mathrm{ijk}}:$ erro associado à subparcela.

Foi realizada análise de regressão utilizando os caracteres SST, ART, POL, ATR e PROTE como variáveis independentes e épocas de colheita $(87,94,101$, $108,115,122,129$ e 136 DAS) como variáveis dependentes e determinado o PUI nas linhas de tendência.

\section{Resultados e Discussão}

O resumo das análises de variância para florescimento, PMV, SST, ART, POL, ATR e PROTE estão apresentados nas Tabelas 1 e 2. Foram verificadas diferenças significativas $(\mathrm{P} \leq 0,05)$ entre as safras agrícolas avaliadas para todos os caracteres, evidenciando que os efeitos ambientais influenciaram de maneira diferente os resultados obtidos nas safras 2011/2012 e 2012/2013. Verificou-se também diferenças significativas $(\mathrm{P} \leq 0,01)$ entre as cultivares avaliadas para todos os caracteres, mostrando diferenças genéticas entre os genótipos avaliados. Houve interação cultivares $\mathrm{x}$ safras significativa $(\mathrm{P} \leq 0,05)$ para quase todos os caracteres avaliados, exceto para SST. Pode-se observar diferenças significativas $(\mathrm{P} \leq 0,01)$ entre as épocas de colheita para todos os caracteres, mostrando haver diferença entre colheitas em diferentes períodos fenológicos da planta de sorgo sacarino. A interação safras $\mathrm{x}$ épocas de colheita foi significativa $(\mathrm{P} \leq 0,01)$ para todos os caracteres. A interação cultivares $\mathrm{x}$ épocas de colheita mostrou-se significativa $(\mathrm{P} \leq 0,01)$ para quase todos os caracteres, exceto PMV. Houve interação safras $\mathrm{x}$ cultivares $\mathrm{x}$ épocas de colheita significativa $(\mathrm{P} \leq 0,01)$ para SST, ART, POL, ATR, e PROTE.

No sorgo sacarino, ao contrário da cana-de -açúcar, o acúmulo de açúcares ocorre após o florescimento (Parrella, 2011) e, desta forma, a maior precocidade das cultivares é desejável para o setor sucroalcooleiro, pois o sorgo sacarino está sendo recomendado para o cultivo em áreas de canaviais em renovação com semeadura nos meses de novembro e dezembro e colheita nos meses de março e abril. Assim, com a utilização de cultivares mais precoces disponibiliza-se mais cedo a área para novo plantio de cana. Foi possível observar pouca variação no número de dias para o florescimento entre as cultivares 
Tabela 1. Resumo das análises de variância para florescimento - FLOR, em (dias), produção de massa verde - PMV, em ( $\mathrm{t}$ ha $\left.^{-1}\right)$, sólidos solúveis totais - SST, em ( $\left.{ }^{\circ} \mathrm{B}\right)$ e açúcares redutores totais - ART, em (\%), avaliados em cultivares de sorgo sacarino em diferentes épocas de colheita, nas safras agrícolas 2011/2012 e 2012/13, Sete Lagoas-MG.

\begin{tabular}{|c|c|c|c|c|c|c|c|c|c|}
\hline $\mathrm{FV}$ & GL & Floresc. & & PMV & & SST & & ART & \\
\hline Safras & 1 & 264,03 & $* *$ & 32178,04 & $* *$ & 362,11 & $* *$ & 52,45 & $* *$ \\
\hline Blocos (safras) & 4 & 1,63 & & 545,53 & & 8,71 & & 8,22 & \\
\hline Cultivares & 4 & 57,87 & $* *$ & 1273,46 & $* *$ & 212,47 & $* *$ & 164,15 & $* *$ \\
\hline Cultivares*Safras & 4 & 35,47 & $* *$ & 432,67 & $*$ & 8,51 & NS & 16,24 & $* *$ \\
\hline Erro 1 & 16 & 21,47 & & 115,74 & & 3,05 & & 2,74 & \\
\hline Épocas & 7 & - & & 2093,47 & $* *$ & 33,25 & $* *$ & 19,25 & $* *$ \\
\hline Safras*Épocas & 7 & - & & 2664,65 & $* *$ & 73,65 & $* *$ & 47,20 & $* *$ \\
\hline Cultivares*Épocas & 28 & - & & 122,60 & NS & 8,57 & $* *$ & 4,52 & $* *$ \\
\hline Safras*Cultivares*Épocas & 28 & - & & 80,14 & NS & 2,63 & $* *$ & 1,84 & $* *$ \\
\hline Erro 2 & 140,0 & - & & 83,85 & & 1,37 & & 0,93 & \\
\hline CV $1(\%)=$ & & 1,41 & & 23,53 & & 13,04 & & 17,12 & \\
\hline $\operatorname{CV} 2(\%)=$ & & - & & 20,02 & & 8,73 & & 9,97 & \\
\hline Média geral: & & 82,43 & & 45,72 & & 13,38 & & 9,66 & \\
\hline
\end{tabular}

**, * e NS: Significativo a 1\%, 5\% e não significativo pelo teste de F, respectivamente.

Tabela 2. Resumo das análises de variância para teor de sacarose aparente (POL), em \%, açúcares totais recuperáveis (ATR), em Kg. $\mathrm{t}^{-1}$ e produtividade de etanol (PROTE), em $1 . \mathrm{t}^{-1}$ de biomassa, avaliados em cultivares de sorgo sacarino em diferentes épocas de colheita nas safras agrícolas 2011/2012 e 2012/13, Sete Lagoas-MG.

\begin{tabular}{|c|c|c|c|c|c|c|c|}
\hline FV & GL & POL & & ATR & & PROTE & \\
\hline Safras & 1 & 37,00 & $* *$ & 698,37 & $*$ & 1588,62 & $* *$ \\
\hline Blocos (safras) & 4 & 10,07 & & 318,96 & & 248,91 & \\
\hline Cultivares & 4 & 188,39 & $* *$ & 8262,62 & $* *$ & 4972,07 & $* *$ \\
\hline Cultivares*Safras & 4 & 20,74 & $* *$ & 928,51 & $* *$ & 491,69 & $* *$ \\
\hline Erro 1 & 16 & 3,51 & & 142,12 & & 82,86 & \\
\hline Épocas & 7 & 22,36 & $* *$ & 906,26 & $* *$ & 582,93 & $* *$ \\
\hline Safras*Épocas & 7 & 55,77 & $* *$ & 2516,46 & $* *$ & 1430,73 & $* *$ \\
\hline Cultivares*Épocas & 28 & 5,13 & $* *$ & 237,04 & $* *$ & 136,97 & $* *$ \\
\hline Safras*Cultivares*Épocas & 28 & 2,24 & $* *$ & 96,46 & $* *$ & 55,53 & $* *$ \\
\hline Erro 2 & 140,0 & 1,17 & & 51,14 & & 28,10 & \\
\hline $\operatorname{CV} 1(\%)=$ & & \multicolumn{2}{|c|}{25,02} & \multicolumn{2}{|l|}{16,20} & \multicolumn{2}{|c|}{17,12} \\
\hline $\operatorname{CV} 2(\%)=$ & & \multicolumn{2}{|c|}{14,48} & \multicolumn{2}{|c|}{9,72} & \multicolumn{2}{|c|}{9,97} \\
\hline Média geral: & & \multicolumn{2}{|c|}{7,48} & \multicolumn{2}{|c|}{73,60} & \multicolumn{2}{|c|}{53,18} \\
\hline
\end{tabular}

**, * e NS: Significativo a 1\%, 5\% e não significativo pelo teste de F, respectivamente. 
avaliadas, com maior variação significativa na safra 2011/2012, de 81 a 87 DAS. A cultivar BRS 511 foi mais precoce nas duas safras avaliadas, com florescimento aos 81 DAS na primeira e 79 DAS na segunda.

Quanto à produtividade de massa verde das diferentes cultivares de sorgo sacarino, na safra 2011/2012, a cultivar XBSW80147 apresentou maior média, 44,56 t.ha-1 ${ }^{-1}$ Na safra 2012/2013, as cultivares BRS 511 e XBSW80147 apresentaram maiores médias com 63,14 e 62,42 t.ha-1 ${ }^{-1}$, respectivamente. Verifica-se que todas as cultivares apresentaram maior produtividade de massa verde na safra 2012/2013. O PMV é um dos caracteres de maior importância para o sorgo sacarino visando a produção de etanol. Lombardi et al. (2015) verificaram forte associação entre produção de massa verde e a produtividade de etanol por hectare. Vale destacar que o caldo rico em açúcares fermentescíveis é extraído em sua totalidade desta biomassa, assim, quanto maior o PMV, maior será a produção de etanol.

Souza et al. (2013), avaliando produção de massa verde de 25 cultivares de sorgo sacarino em cinco localidades no Brasil, observaram produtividades variando de 32 a 57 t.ha $^{-1}, 28$ a 54 t.ha- ${ }^{-1}$ e 25 a 52 t.ha-1, para o BRS 511, BRS 508 e BRS 509, respectivamente. Figueiredo et al. (2015), avaliando produção de massa verde em nove ambientes para as cultivares XBSW80147, BRS 511 e BRS 508, observaram produtividades médias de 39,6 t.ha ${ }^{-1}$, 42,79 t.ha-1 e 37,83 t.ha ${ }^{-1}$, respectivamente. Souza et al. (2016), avaliando produção de massa verde do híbrido XBSW80147 e das variedades BRS 511 e BRS 508, observaram produtividades 75 t.ha $^{-1}, 70$ t.ha $^{-1}$ e 60 t.ha $^{-1}$, respectivamente. Vale salientar que as maiores produtividades foram obtidas em locais e safras favoráveis, ou seja, solos com fertilidade corrigida e boa distribuição de chuvas, mostrando que as condições edafoclimáticas influenciam na produtividade.

As produtividades médias de massa verde variaram com as épocas de colheita, nas duas safras agrícolas. Na safra 2011/2012, ocorreu aumento da PMV de 3,5 t.ha ${ }^{-1}$, a cada sete dias de 87 a 108 DAS, e, em seguida, ocorreu pequena redução de 0,45 t.ha-1, a cada sete dias, até a última avaliação aos 136 DAS. Na safra 2012/2013, ocorreu redução da PMV de 14 t.ha ${ }^{-1}$, a cada sete dias de 87 a 122 DAS e em seguida ocorreu pequeno aumento de 1,0 t.ha ${ }^{-1}$, até a última avaliação aos 136 DAS. É importante destacar a ocorrência de acamamento de plantas nas parcelas experimentais a partir da terceira época de colheita na safra 2012/2013 em razão da ocorrência de chuvas com ventos fortes. Esse fato pode ter contribuído para a redução na PMV nessa safra. Souza et al. (2016) observaram redução na produtividade de biomassa a partir dos 93 DAS até 156 DAS, mas diferencial de acordo o genótipo. Apesar de ser um caráter de grande importância, a produtividade de biomassa não deve ser analisada isoladamente, sendo necessário considerar a concentração de açúcar no caldo extraído dos colmos visando a produção de etanol.

As Figuras 1 e 2 apresentam as variações de SST, ART, POL e PUI para todas as cultivares estudadas, nas duas safras avaliadas. Na safra 2011/2012, ocorreu aumento no teor de sólidos solúveis totais (SST) de $2,70{ }^{\circ} \mathrm{B}, 3,27^{\circ} \mathrm{B}, 3,28^{\circ} \mathrm{B}, 1,34^{\circ} \mathrm{B}$ e 1,38 ${ }^{\circ} \mathrm{B}$ a cada sete dias, de 87 a 108 DAS para as cultivares BRS 511, BRS 508 e BRS 509, Sugargraze e XBSW80147, respectivamente, e em seguida, pequena redução de $0,17^{\circ} \mathrm{B}, 0,23{ }^{\circ} \mathrm{B}, 0,26^{\circ} \mathrm{B}, 0,16^{\circ} \mathrm{B}$ e $0,09^{\circ} \mathrm{B}$ a cada sete dias, respectivamente, até a última época de avaliação aos 136 DAS. Observa-se mais que o dobro de aumento percentual por semana em graus brix nas variedades em detrimento aos híbridos. 
Na safra 2012/2013, para as cultivares BRS 511, BRS 509, Sugargraze e XBSW80147 ocorreu redução no teor de sólidos solúveis totais de $0,33{ }^{\circ} \mathrm{B}, 0,21{ }^{\circ} \mathrm{B}$, $1,91^{\circ} \mathrm{B}$ e $0,79{ }^{\circ} \mathrm{B}$ a cada sete dias, respectivamente, a partir dos 87 DAS até a última época de avaliação aos 136 DAS. Verifica-se maior percentual de redução semanal para os híbridos em detrimento das variedades.

A ocorrência de acamamento das plantas a partir da terceira época de colheita explica a queda na qualidade para a maioria das cultivares. Resultado semelhante foi observado por Fernandes et al. (2014) na avaliação da curva de maturação de quatro cultivares de sorgo sacarino, quando uma das cultivares acamou e apresentou queda de qualidade em detrimento as demais. O acamamento é outra característica de grande importância em sorgo sacarino, pois a sua ocorrência reduz a concentração de açúcar e produção de etanol concomitantemente, além de aumentar as impurezas durante a colheita. O acamamento é dependente do genótipo e do sistema de produção utilizado, necessitando de populações de planta menores que o sorgo granífero e forrageiro, em torno de 120 a 140 mil plantas por hectares (Albuquerque et al., 2012). Contudo, vale destacar a variedade BRS 508, que mesmo com acamamento manteve a qualidade mínima (15 $\left.{ }^{\circ} \mathrm{B}\right)$ por mais de 30 dias. O teor de SST é uma característica que possui correlação positiva com o teor de açúcares totais no caldo e teor de sacarose (Murray et al., 2008; Ritter et al., 2008), os quais são utilizados como alimentos das leveduras na produção de etanol, sendo desejável em maior quantidade possível.

$\mathrm{Na}$ avaliação de 25 cultivares de sorgo sacarino em cinco localidades no Brasil, Souza et al. (2013) obtiveram valores de SST variando de 16,8 a 21,5 ${ }^{\circ} \mathrm{B}, 17,4$ a $21,7{ }^{\circ} \mathrm{B}$, e 17,8 a $21,2{ }^{\circ} \mathrm{B}$, para BRS 511, BRS 508 e BRS 509, respectivamente. Figueiredo et al. (2015), avaliando as cultivares XBSW80147, BRS
511 e BRS 508 em nove ambientes, observaram teores médios de $\mathrm{SST}$ de $14,13{ }^{\circ} \mathrm{B}, 17,66^{\circ} \mathrm{B}$, e 18,81 ${ }^{\circ} \mathrm{B}$, respectivamente. Os teores de SST para as variedades de sorgo sacarino encontradas neste trabalho, na safra 2011/2012, estão de acordo com os trabalhos disponíveis na literatura, que variam de 16 a $21,5{ }^{\circ} \mathrm{B}$ aproximadamente. Esses valores também são equivalentes àqueles observados para cana-de-açúcar na sua maturação plena (Leite et al., 2009).

Os híbridos avaliados apresentaram menores teores médios de SST, $12,2^{\circ} \mathrm{B}$ para o Sugargraze e $15,5^{\circ} \mathrm{B}$ para o XBSW80147, mostrando menor potencial na produção de açúcares e, consequentemente, menor produtividade de etanol. Os valores médios para SST na safra 2012/2013 começaram maiores na primeira época de avaliação quando comparada com a safra 2011/2012, contudo, a ocorrência do acamamento das plantas a partir da terceira época de avaliação causou a redução dos valores, em maior intensidade para os híbridos, limitando o potencial na produção de etanol. Nesta safra, apenas o BRS 508 obteve mais de $15^{\circ} \mathrm{B}$.

O caldo extraído do sorgo sacarino deve apresentar um teor de SST mínimo de $15^{\circ} \mathrm{B}$, equivalente a um teor de açúcares redutores totais em torno de $12,5 \%$, para uma fermentação com alta eficiência e qualidade visando maximizar a produção de etanol (Prasad et al., 2007). Considerando a safra 2011/2012, o BRS 511 durante 30 dias apresentou o teor de SST acima desse mínimo, o BRS 508 com 38 dias, o BRS 509 com 35 dias, o XBSW80147 com 20 dias e o Sugargraze não apresentou o mínimo. Na safra 2012/2013, apenas o BRS 508 apresentou-se acima do mínimo com 49 dias.

As mesmas variações observadas no teor de SST foram verificadas para ART e no teor aparente de sacarose, confirmando a forte correlação en- 


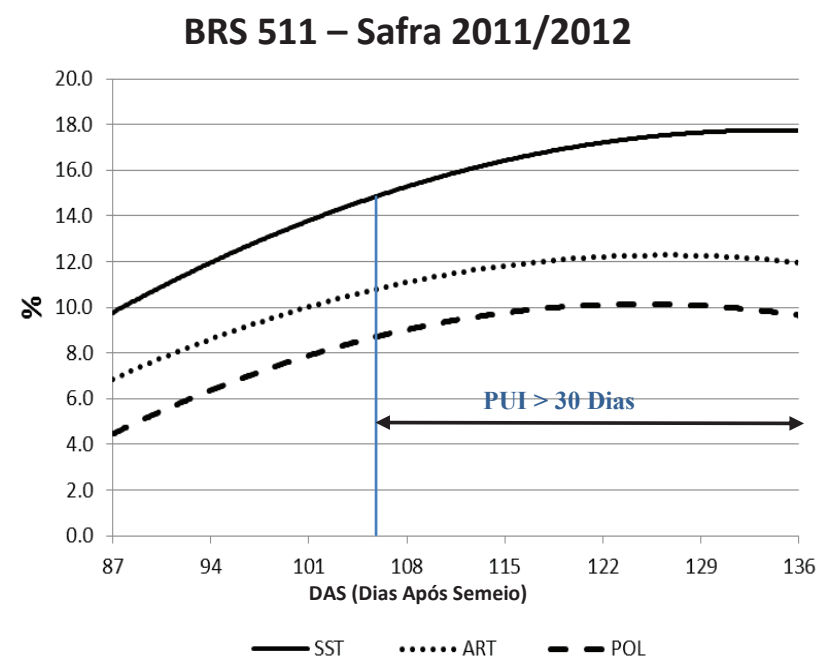

BRS 511 - Safra 2012/2013
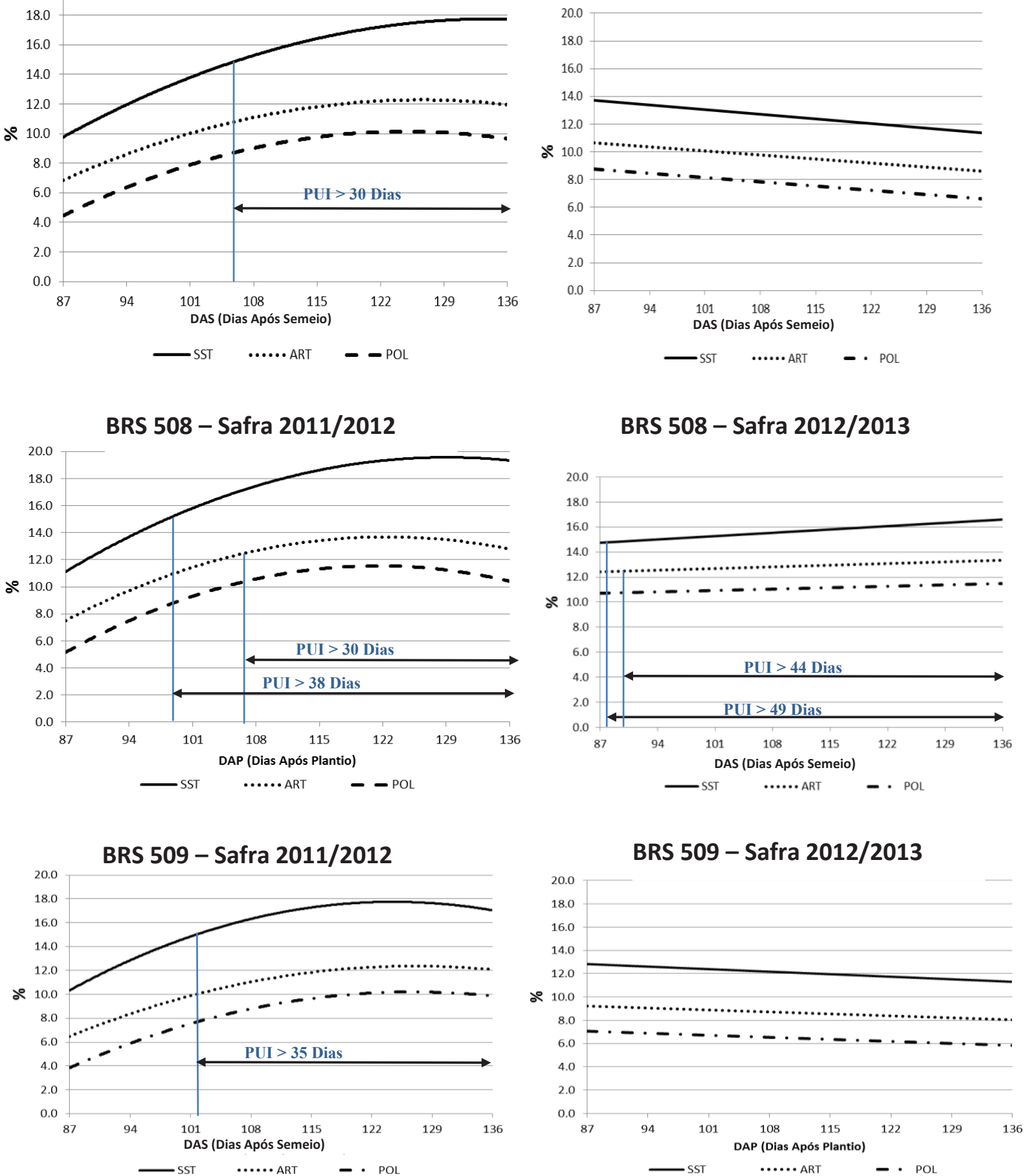

Figura 1. Sólidos solúveis totais - SST, em ${ }^{\circ} \mathrm{B}$, açúcares redutores totais - ART, em \% e teor de sacarose aparente - POL, em \%, avaliados em cultivares de sorgo sacarino BRS511, BRS508 e BRS509, em função de épocas de colheita, avaliadas nas safras 2011/2012 e 2012/2013, Sete Lagoas/MG. 


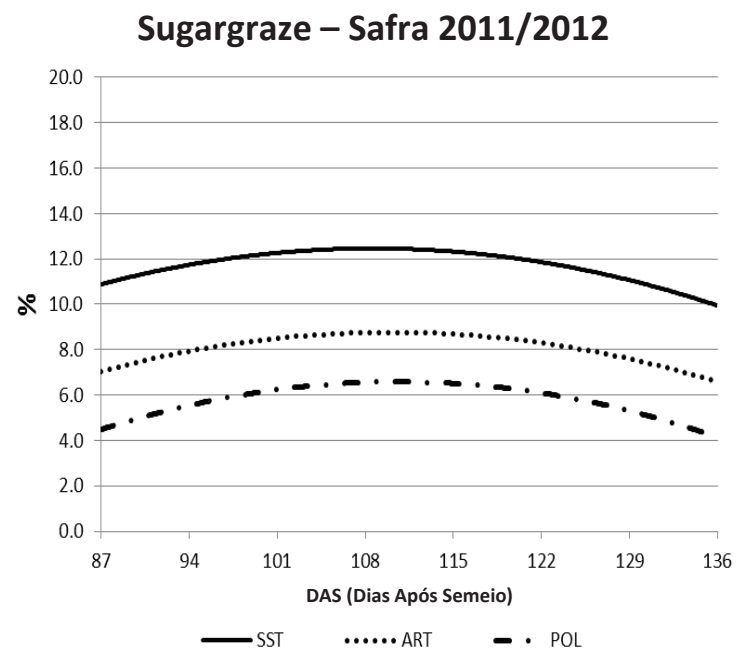

Sugargraze - Safra 2012/2013
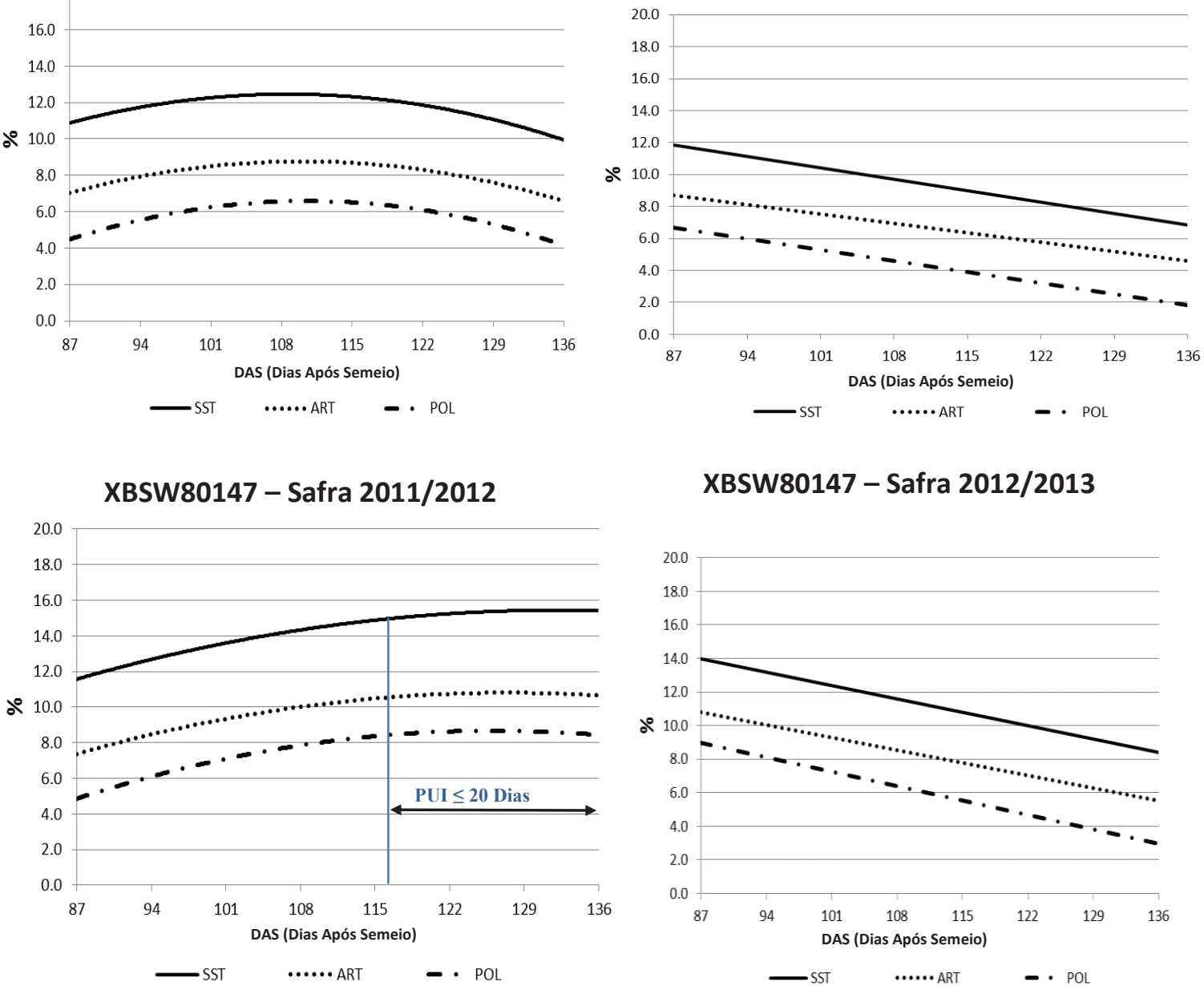

XBSW80147 - Safra 2012/2013

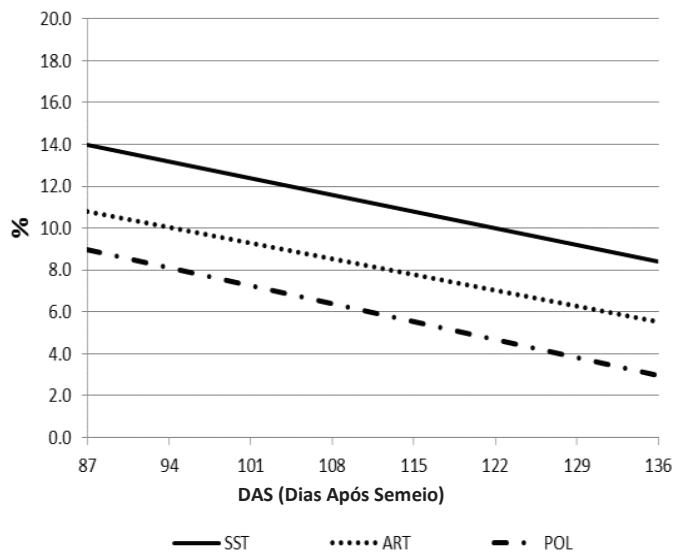

Figura 2. Sólidos solúveis totais - SST, em ${ }^{\circ} \mathrm{B}$, açúcares redutores totais - ART, em \% e teor de sacarose aparente - POL, em \%, avaliados nas cultivares de sorgo sacarino Sugargraze e XBSW80147, em função de épocas de colheita, avaliadas nas safras 2011/2012 e 2012/2013, Sete Lagoas/MG.

tre estes caracteres (Murray et al., 2008; Ritter et al., 2008). Para o teor de ART, na safra 2011/2012, ocorreu aumento de 2,26\%, 2,92\%, 2,42\%, 1,36\% e $1,39 \%$ a cada sete dias, de 87 a 108 DAS para as cultivares BRS 511, BRS 508 e BRS 509, Sugargraze e XBSW80147, respectivamente, e em seguida pequena redução de $0,17 \%, 0,24 \%, 0,18 \%, 0,15 \%$ e $0,10 \%$ a cada sete dias, respectivamente, até a última época de avaliação aos 136 DAS. Maior aumento semanal foi verificado para as variedades em detrimento dos híbridos. Na safra 2012/2013, para as cultivares BRS 511, Sugargraze e XBSW80147 ocorreu redução no teor ART de $0,29 \%, 1,45 \%$ e $0,75 \%$ a cada sete dias, respectivamente, a partir dos 87 DAS até a última época de avaliação aos 136 DAS. Verificou-se maior percentual de redução semanal para os híbridos em detrimento das variedades. O BRS 508 destaca-se por apresentar média em torno de $12,5 \%$, ou seja, dentro 
do mínimo exigido, mesmo com a ocorrência de acamamento das plantas.

Os valores estimados de ART, observados neste trabalho estão subestimados quando comparados aos valores de SST, uma vez que a diferença no valor do ART é em torno de 1,5 a 2\% (Kawahigashi et al., 2013). Neste trabalho, as estimativas foram obtidas de acordo com o Conselho dos Produtores de Cana-de-Açúcar, Açúcar e Álcool do Estado de São Paulo (2006), que padronizou a forma de análises e estimativas para pagamento de cana com base no teor de sacarose. Isso mostra a necessidade de ajuste de tais estimadores para aplicação em sorgo sacarino. Fernandes et al. (2014) avaliaram ART nas variedades de sorgo sacarino BRS 506, BRS 508, BRS 509 e BRS 511 utilizando HPLC (High Performance Liquid Chromatografy) e obtiveram valores de $15,4 \%$, $16,2 \%, 16,5 \%$ e $19,1 \%$, respectivamente. Estes valores são superiores aos obtidos neste trabalho e refletem o potencial do sorgo sacarino na produção de etanol.

Para o teor aparente de sacarose (POL), na safra 2011/2012, ocorreu aumento de 2,49\%, 3,11\%, $2,63 \%, 1,62 \%$ e $1,60 \%$ a cada sete dias, de 87 a 108 DAS para as cultivares BRS 511, BRS 508 e BRS 509, Sugargraze e XBSW80147, respectivamente, e, em seguida, pequena redução de $0,19 \%, 0,26 \%$, $0,19 \%, 0,18 \%$ e $0,12 \%$ a cada sete dias, respectivamente, até a última época de avaliação aos 136 DAS. Verificou-se maior percentual de aumento semanal para as variedades em detrimento dos híbridos. Na safra 2012/2013, para as cultivares BRS 511, Sugargraze e XBSW80147, ocorreu redução no teor aparente de sacarose de $0,30 \%, 0,69 \%$ e $0,85 \%$ a cada sete dias, respectivamente, a partir dos 87 DAS até a última época de avaliação aos 136 DAS. Houve maior percentual de redução semanal para os híbridos do que para as variedades. Os valores observados neste trabalho para teor aparente de sacarose estão abaixo dos valores encontrados para cana-de-açúcar (Henrique et al., 2011). Contudo, Fernandes et al. (2014) observaram teor de sacarose superior a $70 \%$ para as variedades BRS 508 e BRS 511.

As Figuras 3 e 4 apresentam as variações para ATR, PROTE e PUI para todas as cultivares estudadas, nas duas safras avaliadas. O estudo do desdobramento da interação safras x cultivares dentro de cada época de avaliação sofreu influência significativa da interação desses fatores para ATR $\left(\mathrm{Kg} . \mathrm{t}^{-1}\right)$ de biomassa e PROTE $\left(1 . \mathrm{t}^{-1}\right)$ de biomassa.

Para o ATR, na safra 2011/2012, ocorreu aumento de 19,03 Kg.t $\mathrm{t}^{-1}$, 22,43 Kg.t $\mathrm{t}^{-1}$, 20,03 Kg.t ${ }^{-1}$, $11,63 \mathrm{Kg} . \mathrm{t}^{-1}$ e $11,84 \mathrm{Kg} . \mathrm{t}^{-1}$ a cada sete dias, de 87 a 108 DAS para as cultivares BRS 511, BRS 508 e BRS 509, Sugargraze e XBSW80147, respectivamente, e, em seguida, pequena redução de $1,60 \mathrm{Kg}^{-1} \mathrm{t}^{-1}, 1,99$ Kg.t $\mathrm{t}^{-1}, 1,62 \mathrm{Kg} . \mathrm{t}^{-1}, 1,34 \%$ e $1,02 \mathrm{Kg} . \mathrm{t}^{-1}$ a cada sete dias, respectivamente, até a última época de avaliação aos 136 DAS. Verificou-se um percentual de aumento semanal superior para as variedades. Na safra 2012/2013, para as cultivares BRS 511, BRS 509, Sugargraze e XBSW80147 ocorreu redução no ATR de 2,65 Kg.t $t^{-1}$, 1,56 Kg.t $\mathrm{t}^{-1}$, 11,94 Kg.t $\mathrm{t}^{-1}$ e $6,13 \mathrm{Kg} . \mathrm{t}^{-1} \mathrm{a}$ cada sete dias, respectivamente, a partir dos 87 DAS até a última época de avaliação aos 136 DAS. Novamente, o BRS 508 destaca-se por apresentar maior média na primeira safra e estabilidade na segunda.

O ATR deve apresentar uma extração mínima de $80 \mathrm{Kg} \cdot \mathrm{t}^{-1}$ de biomassa visando uma produção eficiente de etanol (Schaffert \& Parrella, 2012). Considerando a safra 2011/2012, o BRS 511 apresentou 33 dias acima desse mínimo, o BRS 508 com 38 dias, o BRS 509 com 32 dias e o XBSW80147 com menos de sete dias e o Sugargraze não apresentou o mínimo. 

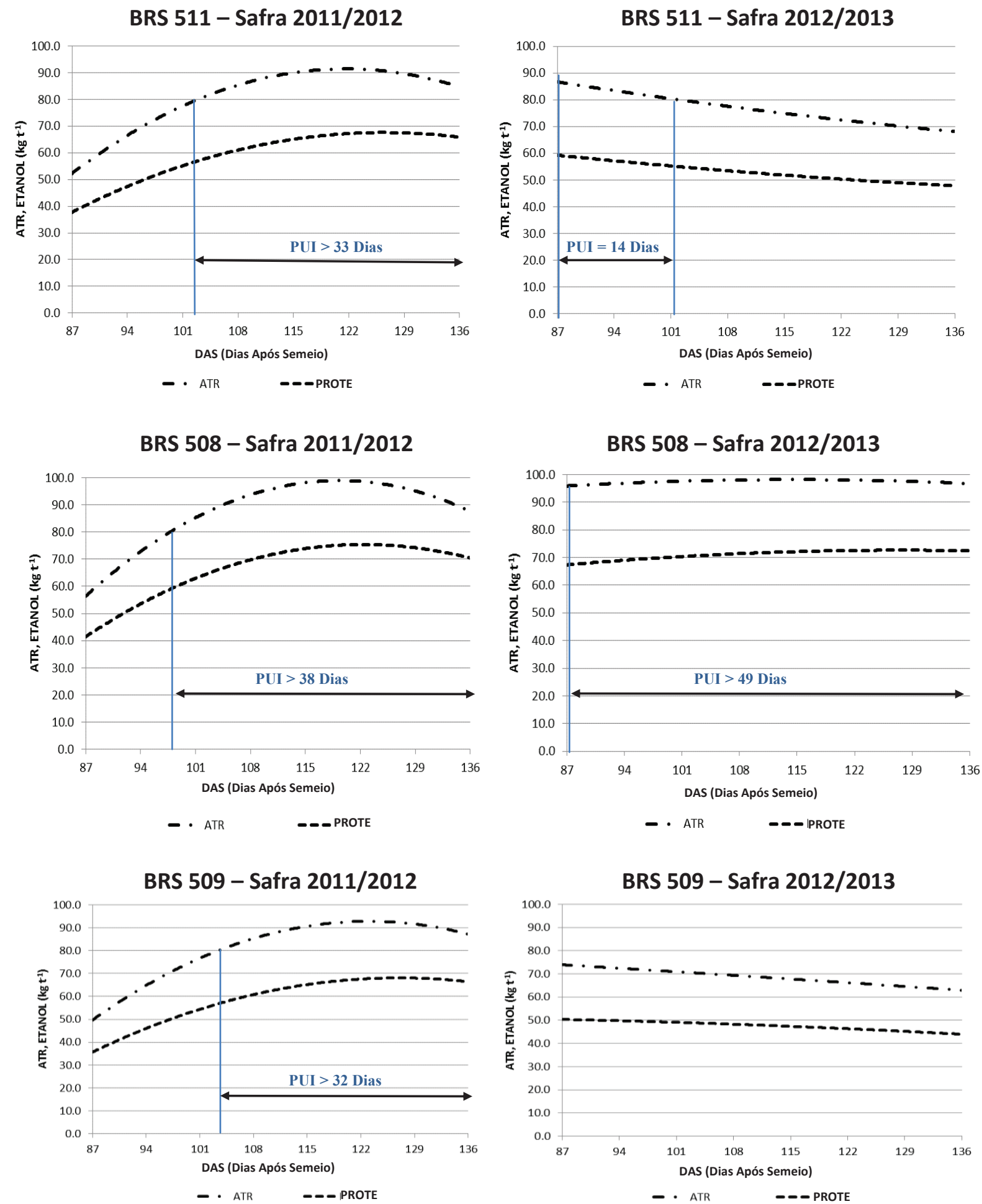

Figura 3. Açúcares totais recuperáveis (ATR), em $t$ de açúcares $\mathrm{t}^{-1}$ de sorgo e produtividade de etanol (PROTE), em 1 de etanol $t^{-1}$ de sorgo, avaliados nas cultivares de sorgo sacarino BRS511, BRS508 e BRS509, em função de épocas de colheita, nas safras 2011/2012 e 2012/2013, Sete Lagoas/MG. 

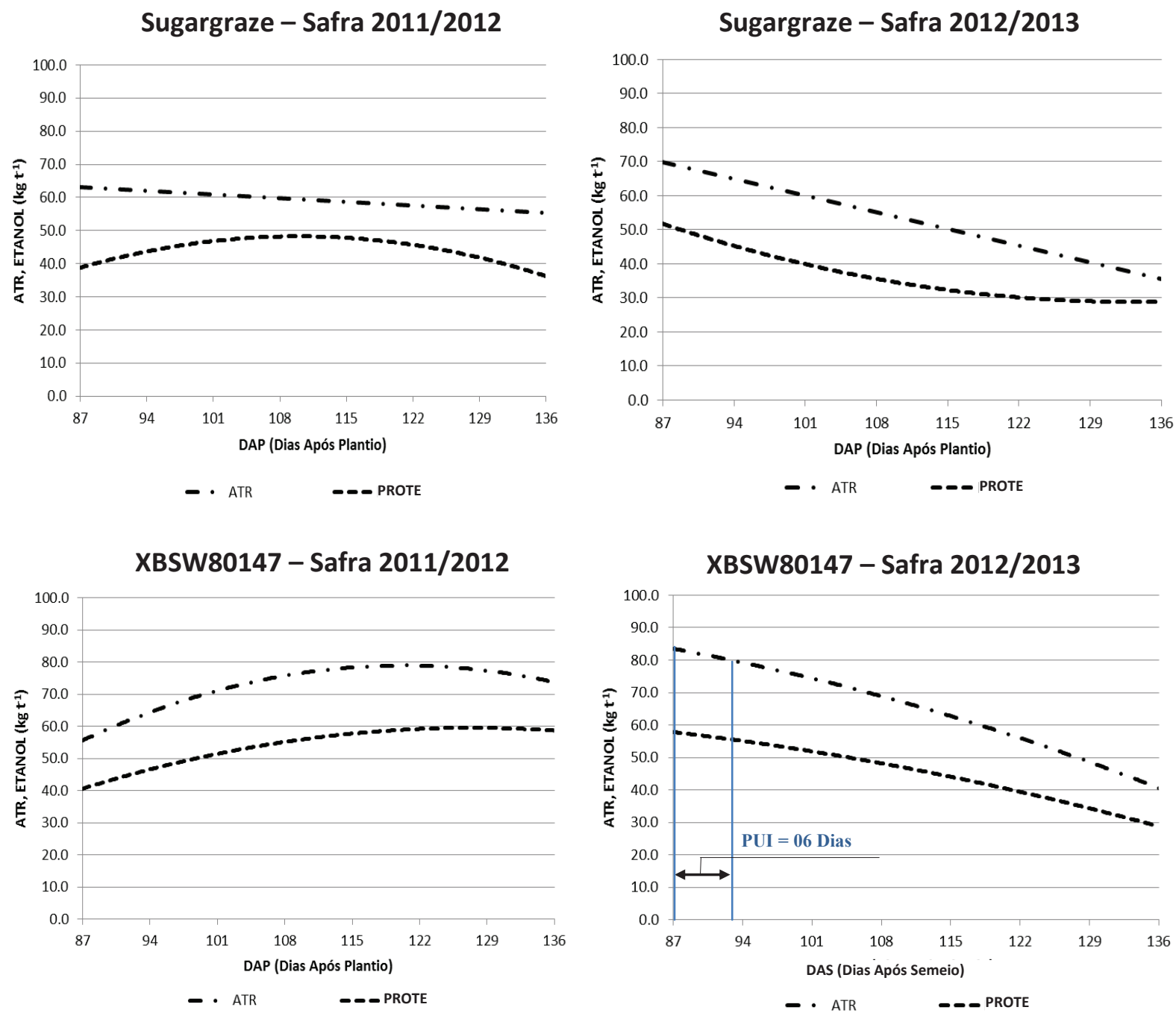

Figura 4. Açúcares totais recuperáveis (ATR), em t de açúcares t- ${ }^{-1}$ de sorgo e produtividade de etanol (PROTE), em 1 de etanol $\mathrm{t}^{-1}$ de sorgo, avaliados nas cultivares de sorgo sacarino Sugargraze e XBSW80147, em função de épocas de colheita, nas safras 2011/2012 e 2012/2013, Sete Lagoas/MG.

Na safra 2012/2013, apenas o BRS 508 apresentouse acima do mínimo por um período de 49 dias. Em cana-de-açúcar, os valores de ATR variam em função do genótipo, ambiente e época de colheita (Santos et al., 2012). Os valores médios variam de $125{\mathrm{Kg} . \mathrm{t}^{-1}}^{-1}$ para a região Nordeste a $146 \mathrm{Kg} \cdot \mathrm{t}^{-1}$ para a região Norte, e média nacional de $132 \mathrm{Kg} \cdot \mathrm{t}^{-1}$, num período de 12 a 18 meses (CONAB, 2016). As variedades (BRS 511, BRS 508 e BRS 509) avaliadas neste trabalho apresentaram ATR com valores médios de 90 a 100 Kg.t ${ }^{-1}$, num ciclo de quatro meses, o que demonstra o potencial dessas cultivares.

Para a PROTE, na safra 2011/2012, ocorreu aumento de $12,451 . t^{-1}, 16,091 . t^{-1}, 13,341 . t^{-1}, 7,491 . t^{-1}$

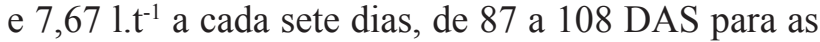
cultivares BRS 511, BRS 508 e BRS 509, Sugargraze e XBSW80147, respectivamente, e, em seguida, pequena redução de $0,931 . t^{-1}, 1,321 . t^{-1}, 0,991 . t^{-1}, 0,87 \%$ 
e $0,561 . t^{-1}$ a cada sete dias, respectivamente, até a última época de avaliação aos 136 DAS. Verificou-se um percentual de aumento semanal superior para as variedades. Na safra 2012/2013, ocorreu aumento de

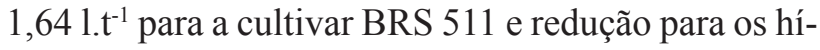
bridos Sugargraze e XBSW80147 de 8,03 1.t-1 e 4,15 $1 . \mathrm{t}^{-1}$, a cada sete dias, respectivamente, a partir dos 87 DAS até a última época de avaliação aos 136 DAS. Mais uma vez, o BRS 508 destaca-se por apresentar maiores médias e estabilidade de produção.

Analisando-se a produtividade de etanol por tonelada de biomassa entre as cultivares, verificou-se na safra 2011/2012 que o BRS 511 apresentou em torno de $701 . \mathrm{t}^{-1}$, o BRS $508 \mathrm{com} 751 . \mathrm{t}^{-1}$, o BRS $509 \mathrm{com}$ $701 . \mathrm{t}^{-1}$, o XBSW80147 com menos $601 . \mathrm{t}^{-1}$ e o Sugargraze apresentou menos $451 . \mathrm{t}^{-1}$. Na safra 2012/2013, apenas o BRS 508 apresentou-se acima do mínimo por um período de 49 dias. As variedades (BRS 511, BRS 508 e BRS 509) avaliadas neste trabalho apresentaram valores médios para ATR de 90 a $100 \mathrm{Kg} . \mathrm{t}^{-1}$, num ciclo de 4 meses apenas, sendo possível visualizar o potencial destas cultivares quando comparadas com a cana-de-açúcar, já que essa apresenta valores maiores, no entanto num ciclo mais longo (12 a 18 meses).

O período de utilização industrial (PUI) é o número de dias em que uma cultivar apresenta ART acima de $12,5 \%$ e extração de açúcar superior a $80 \mathrm{Kg} . \mathrm{t}^{-1}$ com base na extração de açúcar a partir de uma amostra de 500 gramas, utilizando-se uma prensa hidráulica (245 Kg.cm ${ }^{-2}$ durante 60 segundos). Recomenda-se um período mínimo de 30 dias dentro desses limites inferiores, para cada cultivar, visando fornecer maior flexibilidade no planejamento da colheita (Schaffert \& Parrella, 2012). As variedades de sorgo sacarino BRS 511, BRS 508 e BRS 509 apresentaram-se dentro dos limites mínimo de qualidade e produtividade es- tabelecidos na safra 2011/2012 e na safra 2012/2013; apenas o BRS 508 apresentou-se dentro destes limites mínimos. O híbrido XBSW80147 apresentou-se dentro dos limites mínimos de qualidade, mas com um PUI curto, principalmente em relação às variedades. Desta forma, a utilização desta cultivar por usina traz maior risco, uma vez que os atrasos na colheita em usinas são muito comuns e, com isso, perde-se qualidade e produtividade rapidamente, tornando a cultura inviável economicamente. O híbrido Sugargraze não atingiu o mínimo estabelecido nos dois anos de avaliação, mostrando-se um material inadequado para produção de etanol.

Na avaliação das variedades BRS 506, BRS 508, BRS 509 e BRS 511, Fernandes et al. (2014) observaram PUI de 28 dias, 42 dias, 42 dias e 44 dias, respectivamente. Souza et al. (2016) avaliaram híbridos e variedades de sorgo sacarino e observaram um PUI de 35 dias para BRS 508 e 21 dias para XBSW80147. Em ambas as avaliações foi considerado mínimo de $12,5 \%$ de ART no caldo, e o pico de maturação ocorreu aos 115 DAS em média, corroborando com os resultados obtidos neste trabalho.

\section{Conclusões}

As condições climáticas da safra agrícola afetam os caracteres agronômicos e industriais do sorgo sacarino. As cultivares de sorgo sacarino BRS 511, BRS 508 e BRS 509 apresentam melhor desempenho agroindustrial visando a produção de etanol quando comparadas com as cultivares XBSW80147 e Sugargraze. O melhor período de colheita considerando as características agroindustriais foi dos 100 aos 130 dias, apresentando pico aos 113 dias após o semeio. As cultivares avaliadas apresentam períodos de utilização industrial diferentes, com as variedades 
mostrando PUI superior a 30 dias e os híbridos, PUI inferiores a 20 dias.

\section{Referências}

ALBUQUERQUE, C. J. B.; TARDIN, F. D.; PARRELA, R. A. C.; GUIMARÃES, A. S.; OLIVEIRA, R. M.; SILVA, K. M. J. Sorgo sacarino em diferentes arranjos de plantas e localidades de Minas Gerais, Brasil. Revista Brasileira de Milho e Sorgo, Sete Lagoas, v. 11, n. 1, p. 69-85, 2012. DOI: 10.18512/1980-6477/rbms.v11n1p69-85.

CONAB. Companhia Nacional de Abastecimento. Acompanhamento de safra brasileira: $1^{\circ}$ levantamento: cana de açúcar. Brasília, DF, 2016. 61 p.

CONSELHO DOS PRODUTORES DE CANA-DEAÇÚCAR, AÇÚCAR E ÁLCOOL DO ESTADO DE SÃO PAULO. Manual de instruções. Piracicaba, 2006. 112 p.

FERNANDES， G.; BRAGA， T. G.; FISCHER， J.; PARRELLA, R. A. C.; RESENDE, M. M. de; CARDOSO, V. L. Evaluation of potential ethanol production and nutrients for four varieties of sweet sorghum during maturation. Renewable Energy, Oxford, v. 71, p. 518524, 2014. DOI: 10.1016/j.renene.2014.05.033.

FIGUEIREDO, U. J. de; NUNES, J. A. R.; PARRELLA, R. A. da C.; SOUZA, E. D.; SILVA, A. R. da; EMYGDIO, B. M.; MACHADO, J. R. A.; TARDIN, F. D. Adaptability and stability of genotypes of sweet sorghum by GGEBiplot and Toler methods. Genetics and Molecular Research, Ribeirão Preto, v. 14, n. 3, p. 11211-11221, 2015.

DOI: $10.4238 / 2015$.September.22.15.

FERREIRA, D. F. Sisvar: sistema de análise de variância: versão 5.3. Lavras: UFLA, 2010.

HENRIQUE, C. M.; CAMARGO, M. S.; FOLTRAN, D. E.; WYLER, P. Qualidade tecnológica e épocas de colheita de nove variedades de cana-de-açúcar para Tietê/ SP. Colloquium Agrariae, v. 7, n. 1, p. 1-8, 2011.

DOI: 10.5747/ca.2011.v07.n01.a061.
KAWAHIGASHI, H.; KASUGA, S.; OKUIZUMI, H.; HIRADATE, S.; YONEMARU, J. Evaluation of Brix and sugar content in stem juice from sorghum varieties. Grassland Science, v. 59, n. 1, p. 11-19, 2013.

LEITE, G. H. P.; CRUSCIOL, C. A. C.; SILVA, M. A.; VENTURINI, W. G. Qualidade tecnológica da cana-deaçúcar em função da aplicação de maturadores em meio de safra. Bragantia, Campinas, v. 68, n. 2, p. 527-534, 2009. DOI: $10.1590 /$ S0006-87052009000200028.

LOMBARDI, G. M. R.; NUNES, J. A. R.; PARRELLA, R. A. C.; TEIXEIRA, D. H. L.; BRUZI, A. T.; DURÃES, N. N. L.; FAGUNDES, T. G. Path analysis of agro-industrial traits in sweet sorghum. Genetics and Molecular Research, Ribeirão Preto, v. 14, n. 4, p. 16392-16402, 2015. DOI: 10.4238/2015.December.9.8.

\section{MACEDO, I. C. Situação atual e perspectivas} do etanol. Disponível em: <http://www. agencia.cnptia.embrapa.br/Repositorio/ cana2_000g7quvbee02wx5ok0wtedt39a3i85k.pdf $>$. Acesso em: 12 out. 2013.

MURRAY, S. C.; ROONEY, W. L.; MITCHELL, S. E.; SHARMA, A.; KLEIN, P. E.; MULLET, J. E.; KRESOVICH, S. Genetic improvement of sorghum as a biofuel feedstock: II. QTL for stem and leaf structural carbohydrates. Crop Science, Madison, v. 48, n. 6, p. 2180-2193, 2008. DOI: 10.2135/cropsci2008.01.0068.

PARRELlA, R. A. C. Melhoramento genético do sorgo sacarino. Agroenergia em Revista, Brasília, ano 2, n. 3, p. 8-9, 2011.

PARRELLA, R. A. da C.; SCHAFFERT, R. E. Cultivares. In: MAY, A.; DURÃES, F. O. M.; PEREIRA FILHO, I. A.; SCHAFFERT, R. E.; PARRELLA, R. A. da C. (Ed.). Sistema Embrapa de produção agroindustrial de sorgo sacarino para bioetanol: Sistema BRS1G-Tecnologia Qualidade Embrapa. Sete Lagoas: Embrapa Milho e Sorgo, 2012.p. 14-22. (Embrapa Milho e Sorgo. Documentos, 139).

PRASAD, S.; SINGH, A.; JOSHI, H. C. Ethanol as an alternative fuel from agricultural, industrial and urban 
residues. Resources Conservation and Recycling, Amsterdam, v. 50, n. 1, p. 1-39, 2007.

DOI: 10.1016/j.resconrec.2006.05.007.

RITTER, K. B.; JORDAN, D. R.; CHAPMAN, S. C.; GODWIN, I. D.; MACE, E. S.; MCINTYRE, C. L. Identification of QTL for sugar-related traits in a sweet $\mathrm{x}$ grain sorghum (Sorghum bicolor L. Moench) recombinant inbred population. Molecular Breeding, Dordrecht, v. 22, p. 367-384, 2008. DOI: 10.1007/s11032-008-9182-6.

SANTOS, F.; BORÉM, A.; CALDAS, C. (Ed.). Canade-açúcar: bioenergia, açúcar e etanol: tecnologias e perspectivas. 2. ed. rev. ampl. Viçosa, MG, 2012. 637 p.

SANTOS, F. G. dos; CASELA, C. R.; WAQUIL, J. M. Melhoramento de sorgo. In: BORÉM, A. (Ed.). Melhoramento de espécies cultivadas. Viçosa: UFV, 2005. p. 605-658.

SCHAFFERT, R. E.; PARRELLA, R.A. da C. Planejamento industrial. In: MAY, A.; DURÃES, F. O. M.; PEREIRA FILHO, I. A.; SCHAFFERT, R. E; PARRELLA, R. A. da C. (Ed.). Sistema Embrapa de produção agroindustrial de sorgo sacarino para bioetanol: Sistema BRS1GTecnologia Qualidade Embrapa. Sete Lagoas: Embrapa
Milho e Sorgo, 2012. p. 85-92. (Embrapa Milho e Sorgo. Documentos, 139).

SCOTT, A.; KNOTT, M. Cluster-analysis method for grouping means in analysis of variance. Biometrics, Washington, v. 30, n. 3, p. 507-512, 1974.

DOI: $10.2307 / 2529204$.

SOUZA, R. S.; PARRELlA, R. A. da C.; SOUZA, V. F. de; PARRELLA, N. N. L. D. Maturation curves of sweet sorghum genotypes. Ciência e Agrotecnologia, Lavras, v. 40, n. 1, p. 46-56, 2016.

DOI: $10.1590 / \mathrm{S} 1413-70542016000100004$.

SOUZA, V. F. de; PARRELLA, R. A. da C.; TARDIN, F. D.; COSTA, M. R.; CARVALHO JUNIOR, G. A. de; SCHAFFERT, R. E. Adaptability and stability of sweet sorghum cultivars. Crop Breeding and Applied Biotechnology, Londrina, v. 13, n. 2, p. 144-151, 2013.

UNITED NATIONS CONFERENCE ON SUSTAINABLE DEVELOPMENT. The future we want. Rio de Janeiro, 2012. Disponível em: <http:/www.rio20.gov.br/ documentos/documentos-da-conferencia/o-futuro-quequeremos/at_download/the-future-we-want.pdf $>$. Acesso em: 25 ago. 2013. 